\title{
The Effects and Implications of The Use of English as a Medium of Instruction in Mathematics on Thai Learners
}

\author{
David Wafula Waswa ${ }^{1}$
}

${ }^{1}$ Department of Mathematics Education, Faculty of Education, Tshik International University, Erbil, Iraq Correspondence: David Wafula Waswa, Tshik International University, Erbil, Iraq.

Email: david.wafula@tiu.edu.iq

Doi: 10.23918/ijsses.v7i2p89

\begin{abstract}
Education is founded on such fundamental aspects as communication. Acquisition of knowledge can therefore only take place in the presence of effective communication. The medium through which communication takes place assumes a central role in the entire process of learning and teaching. Mathematics concepts, being perceived by many as challenging, require a medium of instruction that is clear and easily understandable by learners. The objective of this study was to determine the effects, opinions and implications of the use of English in teaching Mathematics in Thai public schools. Three instruments; Questionnaires, an Interview Schedule and a written test were employed to realize the objectives. It was established that English as a medium of instruction in teaching Mathematics has fundamental effects on the Thai learners, including but not limited to misperception, demotivation and academic development impairment. The learners suggested code-switching as a medium of instruction.
\end{abstract}

Keywords: Medium of Instruction, Communication, Mathematics, Code-Switching, Misconception

\section{Introduction}

The presence of foreign teachers in Thailand dates back in the nineteenth century when King Mongkut of Thailand gave in to pressure from western powers. In 1855 the country signed the Bowring Treaty with England and similar pecuniary contacts with other Western nations in the following few years (Darling \& Darling, 1971). Although Thailand avoided imperialistic colonization by Western powers, she was unable to escape the web of neo-colonial influences (Tripasai, 2005), which gave rise to English education for royalty and the aristocracy, and then modern education for the common people. King Mongkut established a palace school and hired foreign teachers to teach English language and culture to his royal family who would later help him to administer the kingdom. Since then, English was taught primarily as a foreign language at a governmental level for a long time, until the authorities recognized that English can open many doors for the citizens as it was the most widely used language in the world (Oxford Advanced learners Dictionary, 2005). It is against this background that the Thai government sought to establish Mini language schools in various government schools throughout the country, to teach and use English as a medium of instruction in all subjects, Mathematics included. Mathematics as a subject takes a prominent position in the hierarchy of subjects in the curriculum. Being a science and an art, mathematics plays a major role not only in bridging the conceptualization of the subtle elements in pure and social sciences, but also in developing the analytical ability of learners. Therefore, given the importance of mathematics as a subject, most educational systems in the world make it a compulsory subject in primary and secondary school curricula. In Thailand for instance, mathematics is taught at all levels from elementary to high 
school but for the most part, it has been taught in Thai language, which is both the national and official language.

\subsection{Statement of the Problem}

English Language Learners (ELL) often experience difficulties in using English as a sole medium of communication in Mathematics classrooms (Freeman, 2012). This perceptibly leads to poor communication in the said classrooms, which in turn is reflected in the performance of mathematics by students in English program Departments in schools. The Thai government set up Mini English Programs (MEP) in order to foster the English level among students (Sangnapaboworn, 2003), but still the government's effort to this end is yet to be seen. In many mathematics classrooms students experience challenges in asking questions to clarify where they did not understand. Learners also cannot express themselves well when answering questions in class; instead, they prefer board-work with little or no speaking. It is common for learners to use dictionaries during examinations, a practice that often leads either to examination malpractices or wastage of time. Students spend too much time referring to dictionaries even for simple vocabulary used in mathematics questions, eventually run out of time and not answering all questions on the examination paper. It is also common for students to avoid word problems in exercises and examinations. Besides classroom issues, there is a significant reduction in the number of students who actually complete the programs and exit after finishing grade twelve. It has been observed that only less than half of the students who enroll in grade seven actually finish the program, the rest opt out in between the years, to join other programs such as gifted Mathematics or gifted Science, even gifted English! Many of the gifted programs are taught by Thai teachers who speak little or no English at all in their classrooms, even when they teach English. Could the use of English as a service language in Mathematics be one of the factors contributing to this mass exit from the English programs?

This study was designed to find out the effects of using English as a medium of instruction in the learning of Mathematics on Thai learners. English is used by teachers in the process of teaching and it is also used in mathematics text books, therefore the study explored how both cases affect learners, and their opinions on how English is used as mentioned above, and the implications thereof, such as university placements and dropout rate of students from the program. To achieve this, the following questions were crafted and used to guide the study:

1. What are the effects of the use of English as a medium of instruction in the learning of Mathematics on Thai learners?

2. What are the Thai learners' opinions of the use of English as a medium of instruction in mathematics?

3. What are the implications of the use of English as a medium of instruction in the learning of Mathematics on the learners?

\subsection{Research Objectives}

Accordingly, the research objectives are:

1. To find out the effects of the use of English as a medium of instruction in the learning of Mathematics

2. To investigate the Thai learners' opinions of the use of English as a medium of instruction in Mathematics. 
3. To determine the implications of the use of English as a medium of instruction in the learning of Mathematics on the Thai learners

\subsection{Research Hypotheses}

Objectives number 2 and 3 are hypothesis free but objective number 1 has a hypothesis and is stated in the null as follows;

$\mathrm{H}_{\mathrm{O}}$ : There are significant effects of the use of English as a medium of instruction in the learning of Mathematics on Thai learners' achievement.

\subsection{Theoretical Framework}

This study was based on the cognitive development theory which is concerned with the cultural context as an integral part of developmental psychology. It takes into consideration the synthesis between the more traditional theories that emphasis age-related, internally driven processes and the analysis of the cultural context. This theory by Vygotsky, deals with the processes that explains children's development with time and the influence on perspectives that emphasize the cultural tools and social interaction, as well as logic and actions in the physical world. With its emphasis on the use of language in the learning of Mathematics, the study also employed the communication theory, originally by Claude Elwood Shannon, which takes language as an instrument of communication as shown in figure. 1 below.

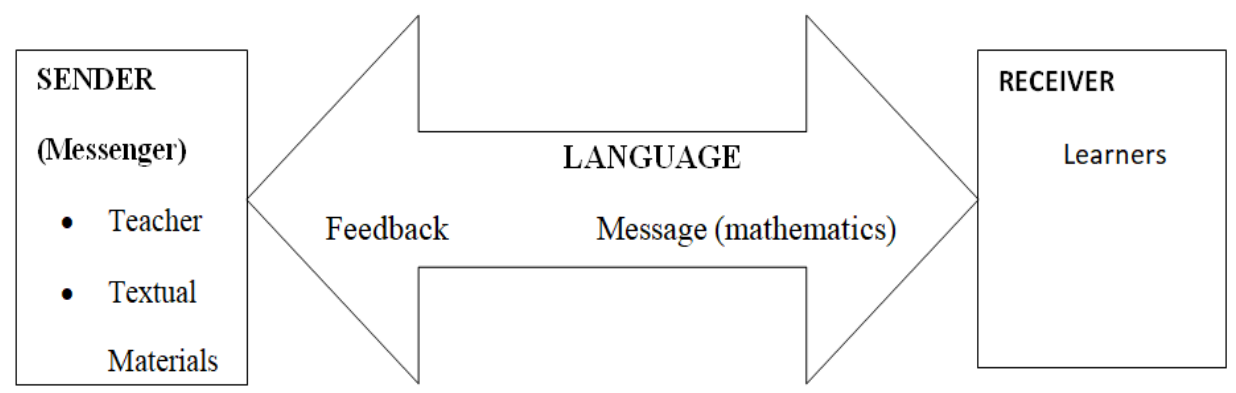

Figure1: Communication Theory

The most pertinent elements of communication as depicted in Figure 1 above are the message, the messenger, the receiver, encoding, decoding and the channel. In this research, the message is Mathematics, the teacher is the messenger, the student is the receiver and encoding refers to the verbal and non-verbal convention of communication of Mathematical concepts through language. Decoding, on the other hand, is the reading (understanding the Mathematical language) by the receiver of the encoded message done by the messenger and English as a language of instruction is the channel, the means of communication. Language of communication in this study includes the language used in the textual materials and the oral communication that goes on between the teacher and amongst student.

\subsection{Conceptual Framework}

Figure 2 below show the conceptual framework that outlines both dependent and independent variables in the study. 


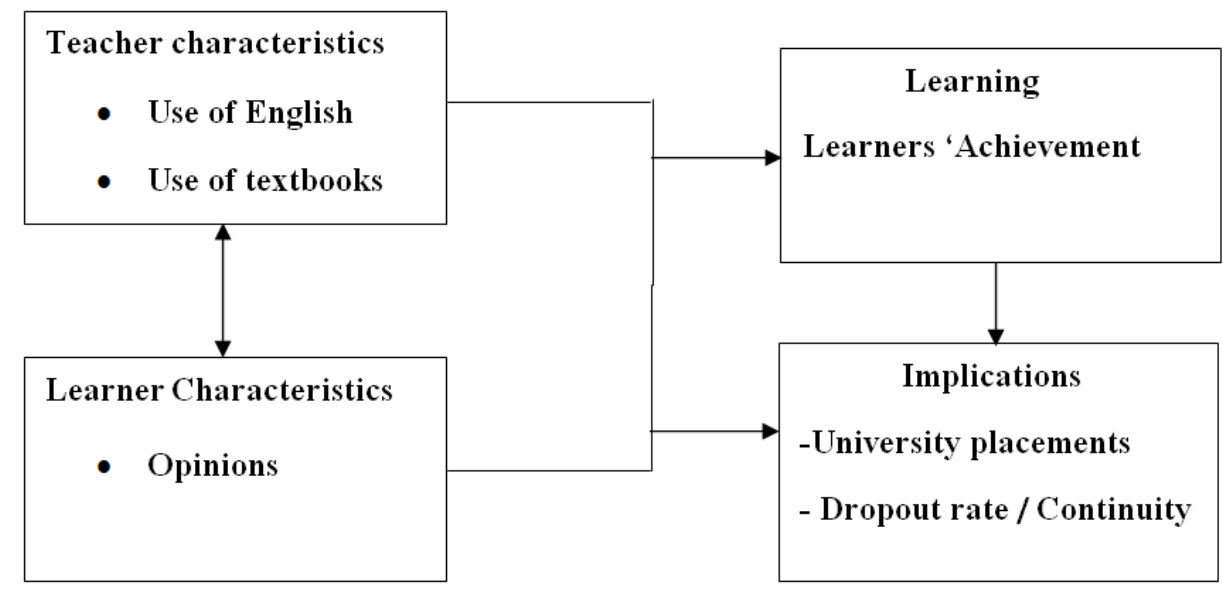

Figure 2: Conceptual framework

\subsection{Significance of the Study}

The significance of this study is threefold. First, this study is especially relevant to the curriculum developers, specifically mathematics curriculums whose end users are not proficient in the use of English language. This is particularly important because curriculum consumers must be able to understand, absorb and assimilate the curriculum for it to be effective.

The mathematics curriculum developers need to put into account the level of English usage by the end users of the curriculum so that they can adjust accordingly to suit their target groups. If the medium used in the development of the curriculum is too complicated for the consumers, a lot of time will be wasted in interpreting the curriculum instead of learning the concepts being put forward. Writers of Mathematics books being in the same category as curriculum writers may benefit from this research. They too need to understand the level of English usage by their target consumers. This would help them in the selection of vocabulary to be used in their books, so that users do not waste a lot of their time trying to understand the language. Consequently, it becomes easy for them to understand the concepts faster and the subject would certainly appear a bit interesting if not easier.

Secondly, this investigation into the use of English as a service language in the instruction of mathematics may come up with results that might improve the standards of instruction of mathematics, hence by extension lift the performance in the subject by learners through better understanding of the underlying concepts. In this regard, instructors need a comprehensive understanding of their learners' abilities and inabilities of usage of English language. This can help instructors in two obvious ways; one, if they understand the short-comings or strong points of their students in regard to English language, then they can easily adjust their vocabulary to suit the students. Two, in selecting the textual materials to be used by the students, this has to be done in such a way that the language used in the selected textual materials suits or can be understood easily by the learners. 
Thirdly, this study will undoubtedly enlighten learners on the effects and implications of the service language on understanding of the subject matter and overall achievement in the subject. With this in mind, they can make an informed choice of what service language would be better for them. If no choice is available for them, then they can perhaps use textual materials written in the language they understand better to further their understanding of the concepts taught through an alien language.

\section{Research Design and Methodology}

This is a cross-sectional survey research which examined data from questionnaires, classroom observations and an interview. Questionnaires were filled by teachers and students, and the head of the English Program was interviewed. The research was to establish the effects of using English to teach Mathematics on the Thai learners, and thus to establish whether the required necessary communication actually takes place in the classrooms, and whether the English used in the textual materials match the level of English of the learners.

\subsection{Population and Sample}

The population comprised of students and teachers from a government school in Ratchaburi municipality. Ratchaborikanukroh is a mixed day secondary school with students from diverse socio-economic backgrounds, assumed to be a proper representation of the entire region. 9 foreign teachers and 141 lower secondary students were given questionnaires to answer. Both teachers and students represent the entire population because the research used all the Mathematics teachers in the school and students from grade 7 , grade 8 and grade 9 from the same school.

\subsection{Research Instrument}

Three instruments; the questionnaires, an interview form and a written test were employed to realize the set objectives.

\subsubsection{Questionnaires}

Two questionnaires were used, one for the teachers of Mathematics and another one for the learners. The teachers' questionnaire contained 23 items while the students' questionnaire contained 30 items divided into two parts to determine their opinions of the use of English in learning Mathematics as well as problems that they face when English is used in the teaching of Mathematics. The choices of answers were given on a Likert scale as follows; 'Strongly Agree', 'Agree', 'Disagree' and 'Strongly Disagree'. Since the sample size was small, the research gave the questionnaire to each respondent, monitored the progress and collected the questionnaire after the subject had finished, resulting in $100 \%$ feedback.

\subsubsection{Interview}

The interview had 20 items whose aim was to do a quick and accurate analysis of the school recodes. The items were designed to give the analysis of the records in terms of the number of students who drop out of school each year, the number of students who get admission in which Universities, and the number of those who get admitted to Universities and take up courses that require a strong background in Mathematics. 


\subsubsection{Written Test}

A comprehensive test on three units; Percentages, Ratios and Proportions, and Transformations, was administered to grade 8 students twice, the first time in English and then two months later the same test was administered in their native Thai language. The rational for choosing grade 8 students was that it was the middle class of lower secondary school system in Thailand.

\subsection{Validity and Reliability}

Content validity was established by the Table of specification following Rovinelli \& Hambleton's Index of Item-Objective Congruence (1977). After which three experts in the field of study rated the items regarding how well they tapped the objectives and the ratings were as follows:

$1=$ Item clearly taps the objective

$0=$ Unsure/Unclear

$-1=$ Item clearly does not tap the objective

The correctness of the questions was then checked for reliability using SPSS 16.0 in calculating the coefficient of alpha based on Cronbach, the results were 0.743 for the students' questionnaire and 0.782 for students questionnaire. Three experts were also used to ascertain the face and content validity of Mathematics Test (MT), Teachers' Questionnaire (TQ), Students' Questionnaire (SQ) and the Administrator's Interview (AI). Kothari (2004) notes that validity is the extent to which a measuring instrument provides adequate coverage of the topic under study, if the measurements contain a representative sample, then content validity is good. The suggestions made by the experts were used to revise the instruments before collecting data.

\subsection{Pilot Study}

A pilot study was carried out to establish the suitability of the instruments to be employed. Its purpose was to find out whether the items on the instrument would easily be understood by the target group. Results were subjected to an SPSS test to verify authenticity of the questionnaire.

\subsection{Data Analysis}

The following Statistical Methodologies were used in SPSS 16.0 to realize the research objectives:

Objective 1: To find out the effects of the use of English as a medium of instruction in the learning of Mathematics: Frequency and percentiles were used.

Objective 2: To investigate the learners' opinions of and attitudes towards the use of English as a language of instruction in Mathematics: Frequency and percentiles were used.

Objective 3: To determine the implications of the use of English as a medium of instruction in the Learning of Mathematics on the learners: Means, percentiles and a Paired Samples t-test were used.

Table 1 below gives a summary of the entire research process ranging from the research objectives through the source of data, how the data was collected, analyzed to the expected outcome of the research. 
Table 1: Summary of the Research Process

\begin{tabular}{|c|c|c|c|c|}
\hline Research Objective & $\begin{array}{c}\text { Source of Data } \\
\text { or Sample }\end{array}$ & $\begin{array}{c}\text { Data Collection } \\
\text { Method }\end{array}$ & Data Analysis & Expected outcome \\
\hline $\begin{array}{l}\text { 2. To investigate the } \\
\text { learners opinions of } \\
\text { the use of English as a } \\
\text { language of } \\
\text { instruction in } \\
\text { Mathematics. } \\
\text { 3. To determine the } \\
\text { implications of the use } \\
\text { of English as a } \\
\text { medium of instruction } \\
\text { in the learning of } \\
\text { Mathematics on the } \\
\text { learners }\end{array}$ & $\begin{array}{l}\text { Teachers } 9 \\
\text { Students } 141 \\
\text { Students: } 19\end{array}$ & $\begin{array}{l}\text { Teachers: } \\
\text { Questionnaires } \\
\text { Students: } \\
\text { Questionnaires } \\
\text { Students: written } \\
\text { test } \\
\text { Teachers: } \\
\text { Questionnaires } \\
\text { Students: } \\
\text { Questionnaires } \\
\text { Administrator's: } \\
\text { Interview }\end{array}$ & $\begin{array}{l}\text { Frequencies: Means } \\
\text { \& percent } \\
\text { Frequencies: Means } \\
\text { \& percentages } \\
\text { Paired Samples } \\
\text { t-test } \\
\text { Frequencies: Means } \\
\text { \& percentages } \\
\text { Frequencies: Means } \\
\text { \& percentages }\end{array}$ & $\begin{array}{l}\text { learners opinions } \\
\text { of the use of } \\
\text { English as a } \\
\text { language of } \\
\text { instruction in } \\
\text { Mathematics } \\
\text { The implications } \\
\text { of the use of } \\
\text { English as a } \\
\text { medium of } \\
\text { instruction in the } \\
\text { learning of } \\
\text { Mathematics on } \\
\text { the learners }\end{array}$ \\
\hline
\end{tabular}

\section{Literature Related to the Problem Statement}

Teaching mathematics with an understanding that students have Limited English proficiency (LEP) offers them an opportunity to increase their English fluency at the same time as they acquire other skills. But more importantly, they may develop the ability to communicate their answers and the reasons for them. All this can only be possible with proper classroom instruction. Gagné (1985) explicitly put it that instruction forms the backbone of education. Therefore, if the instruction is not understood then learning may not have occurred. Instruction involves language; hence learners must understand the language in order to follow the instructions. This is more so in Mathematics as suggested by Post (2009), that emphasize must be put on language to make sure that it is understood before symbols for operation are introduced. Post further underscored the importance of conversations in a classroom, phrases like "multiply by", "times", and "lots of" are used interchangeably by students and so small talks in the classroom may eliminate the problem, or that of "divided by" and "divided into", which is cause of confusion for learners. Ryan (2003) attributes the poor performance in Mathematics word problems to lack of understanding of the language by students. The Van Hieles, cited by Troutman and Lichtenberg (2003), concluded that obstacles in communication exist between students and teachers as well as between students and text books, and Francis et al (2006) highlighted the importance of "academic language" as one of the pillars of learning, especially mathematics. Therefore, the language of instruction in Mathematics should be as clear as it can possibly be to lessen the burden of language minority mathematics learners. In Improving Mathematics Instruction, teachers need theories, empirical research, and alternative images of what implementation of problem solving strategies looks like (Stigler et al: 2004). Steele (2009) would add that teachers need to be adept at improvising, interpreting events in progress, testing 
hypotheses, demonstrating respect, showing passion for teaching and learning, and helping students understand complexity. All these involve best teaching practices which include classroom management as a way of effective teaching (Danielson, 2007).

\section{Results and Discussion}

In this chapter, the results of the research done using the various instruments discussed in chapter three are presented. The aim of the research was to try to answer the following research questions: What are the effects of the use of English as a medium of instruction in the learning of Mathematics on Thai learners, what are the learners' opinions of the use of English as a language of instruction in mathematics? And finally, what are the implications of the use of English as a medium of instruction in the learning of Mathematics on the learners? By answering these questions, the researcher would have achieved the objectives set out at the beginning of the research. Using figures, tables and charts where possible, data analyzed is presented.

\subsection{Respondents' Biodata}

Female students accounted for majority of the student respondents with $54.6 \%$ while male teachers accounted for $66.7 \%$ of the teachers who responded. The results also indicate that almost all students (97.2\%) enrolled in the English Program in grade 7, at entry level. This eliminates the question of disparity in exposure to the English language.

\subsection{Research Findings}

Results are presented in chronological order of the objectives beginning with the first objective.

\subsubsection{Effects of Using English as a Medium of Instruction in the Learning of Mathematics}

Teachers in general feel that the necessary communication needed for learning does not take place in the classrooms as majority of them (66.7\%) say students do not ask questions in class and less than a quarter of them say students answer questions in class when asked. However, about three-quarters of them agree that English produces a better classroom environment. 58.1\% of students concur with teachers that they do not ask questions in class, and slightly more than three-quarters of them agree with teachers about answering questions in class. A large majority of students $(61 \%)$ indicate that teachers use difficult vocabulary, which may explain why slightly more than half of them do not understand instructions given by teachers, and $55.3 \%$ do not speak English in class at all. Slightly more than three-quarters of the teachers concede that setting tests and examinations using English is easier than any other language, and majority of them $(44.5 \%)$ think that the learners' lack of proficiency in the English language hinders their performance in the tests and examinations. However, an overwhelming majority of the students disagree with teachers as slightly more than two-thirds reported that vocabulary in the tests was not easy. This therefore, lends credence to the fact that both parties agree that students are not able to read Mathematics text books without dictionaries, and slightly more than three-quarters of the students agree that group discussions done in English are not effective. In terms of overall use of English, teachers agree that the use of English slows down the lesson (66.7\%) but disagree that it bolsters students' interest in mathematics. They also disagree, together with students, that it helps students understand mathematics better and that it makes students neglect mathematics $(66.7 \%)$. However, two-thirds students of the students think that it 
helps them become better communicators. To sum it up, a paired samples t-test showed a significant difference between tests done in English language and those done in Thai language.

Table 2: Summary of the results on communication

\begin{tabular}{|c|c|c|c|c|c|c|}
\hline \multirow{2}{*}{ Communication } & \multicolumn{3}{|c|}{ Teachers \% } & \multicolumn{3}{|c|}{ Students \% } \\
\hline & Yes & No & $\mathrm{Ntl}$ & Yes & No & $\mathrm{Ntl}$ \\
\hline Difficult English vocabulary & & & & 61 & 36 & 3 \\
\hline Do not understand instructions given in English & & & & 51.8 & 46.8 & 1.4 \\
\hline Do not ask questions in class & 66.7 & 11.1 & 22.2 & 58.1 & 38.3 & 3.5 \\
\hline Do not answer questions in class & 33.3 & 22.2 & 44.5 & 73.8 & 22.7 & 3.5 \\
\hline Do not speak English in class & & & & 55.3 & 41.9 & 2.8 \\
\hline Can read and understand text books & 33.3 & 55.6 & 11.1 & 47.8 & 48.9 & 3.3 \\
\hline Enjoy & & & & 27 & 67.4 & 5.6 \\
\hline The teacher is unable to go deeper into content & 44.4 & 44.4 & 11.2 & & & \\
\hline Explains the language used in the math text books & & & & 68.8 & 28.4 & 2.8 \\
\hline English produces a better classroom environment & 66.6 & 22.3 & 11.1 & & & \\
\hline Use easy vocabulary & & & & 24.8 & 70.9 & 4.3 \\
\hline Easy to set & 66.7 & 22.2 & 11.1 & & & \\
\hline English leads to poor performance in math & 44.5 & 33.3 & 22.2 & & & \\
\hline Read without dictionaries & 22.2 & 44.5 & 33.3 & 25.5 & 70.2 & 4.3 \\
\hline Do not understand when English language is used & & & & 77.3 & 19.8 & 2.8 \\
\hline $\begin{array}{l}\text { English slows down the lesson } \\
\text { English help them become proficient communicators }\end{array}$ & 66.7 & 22.2 & 11.1 & $\begin{array}{l}61.0 \\
61.0\end{array}$ & $\begin{array}{l}32.6 \\
31.9\end{array}$ & $\begin{array}{l}6.4 \\
7.1\end{array}$ \\
\hline Make it difficult to switch schools & & & & 51.8 & 44.0 & 4.3 \\
\hline English help them understand Mathematics better & 33.3 & 44.5 & 22.2 & 23.4 & 70.9 & 5.7 \\
\hline English could bolster students' interest in learning Mathematics & 22.2 & 66.7 & 11.1 & & & \\
\hline Students neglect mathematics because it is taught in English & 22.2 & 66.7 & 11.1 & & & \\
\hline
\end{tabular}

\subsubsection{Opinions of the Use of English as a Language of Instruction in Mathematics}

Majority of the students (38.3\%) were not sure whether English boosts their power to communicate or not. But more than half $(56.8 \%)$ of them were of the opinion that Mathematics word problems were difficult to do, and therefore suggest that the teacher should speak very slowly for students to understand. Almost the same number $(55.3 \%)$ of students also thought that the teachers should explain some concepts in Thai language, but teachers were of a different opinion as $66.7 \%$ of them thought code-switching in class is not appropriate, indeed most of them feel that teaching in English is easier than teaching in Thai. When teachers were asked whether the Mathematics textbook was difficult for their students to read and understand, $44.5 \%$ of them were affirmative, although a relatively big number (33.3\%) was undecided. But when they were asked whether Mathematics textbooks should have some explanations written in Thai language, there was no consensus. However, both teachers and students agreed with the opinion that Mathematics textbooks may be difficult for students to read. This appears to be contrary to another seemingly popular opinion among students that mathematics tests set in English are easier to do as compared to those set in Thai language. Students (58.2\%) also were of the opinion that dictionaries should be used at all times, especially when doing assignments and exercises. They were also content that mathematics group discussions should be conducted in Thai language $(71.7 \%)$ because it is not easy to explain mathematics concepts in English (81.7\%). More than half of the teachers $(55.6 \%)$ are of the 
opinion that complementary mathematics lessons should be given in Thai language, an idea supported by $64.5 \%$ of the students. This may be because most students like mathematics (55.4\%) and they think that it is important $(64.6 \%)$. Teachers on the other hand support supplementary lessons perhaps because most of them $(55.6 \%)$ are of the opinion that teaching mathematics in English is not easy. It should be noted that popular as the opinion of supplementary lessons in Thai language may be, still almost half of the teachers (44.4\%) disagreed with it.

Table 3 Summary of the opinions of the use of English in teaching Mathematics

\begin{tabular}{|c|c|c|c|c|c|c|}
\hline \multirow{2}{*}{ Communication } & \multicolumn{3}{|c|}{ Teachers \% } & \multicolumn{3}{|c|}{ Students \% } \\
\hline & Yes & No & Ntl & Yes & No & $\mathrm{Ntl}$ \\
\hline English boost power to communicate & & & & 29.8 & 31.9 & 38.3 \\
\hline Mathematics word problems were difficult to do & & & & 56.8 & 37.5 & 5.7 \\
\hline $\begin{array}{l}\text { The teacher should speak very slowly for students to } \\
\text { understand }\end{array}$ & & & & 53.2 & 45.4 & 1.4 \\
\hline The teacher should explain some concepts using Thai language & & & & 55.3 & 24.8 & 19.9 \\
\hline The teacher is the deciding factor & & & & 52.5 & 39.7 & 7.8 \\
\hline The teacher should not code-switch in class & 66.7 & 22.2 & 11.1 & & & \\
\hline It is easy to teach in English & 44.5 & 22.2 & 33.3 & & & \\
\hline Mathematics text books are difficult to read & 44.5 & 22.2 & 33.3 & 56.7 & 38.3 & 5 \\
\hline Mathematics text books should be written in Thai & 33.3 & 33.3 & 33.3 & 53.2 & 43.3 & 3.5 \\
\hline Mathematics tests in English are easy to do & & & & 49.7 & 46 & 4.3 \\
\hline Students should do exercises without dictionaries & & & & 37.5 & 58.2 & 4.3 \\
\hline Group discussions to be conducted in Thai language & & & & 71.7 & 22.7 & 5.7 \\
\hline It is easier to explain in English than in Thai & & & & 2.3 & 81.7 & 16 \\
\hline Supplementary lessons should be given in Thai & 55.6 & 44.4 & 0.00 & 64.5 & 30.5 & 5.0 \\
\hline Like mathematics & & & & 55.4 & 29.0 & 15.6 \\
\hline Math is important & & & & 64.6 & 25.5 & 9.9 \\
\hline Difficult to teach in English & 55.6 & 22.2 & 22.2 & & & \\
\hline
\end{tabular}

\subsubsection{Implications of using English in Mathematics on Thai learners}

\subsubsection{Teacher Tenure}

The length of stay of a teacher in the school has far reaching implications. From the table below, we see that 2 teachers had been in the school for less than 1 year, 3 teachers had been there for only 2 years and 4 had been with the school for more than 3 years.

\subsubsection{Enrolment Rate}

Majority of teachers (55.6\%) disagree that the use of English in classroom leads to low enrolment of students in schools. But the records show that of all the students who enroll in grade 7 (first grade of secondary school), only about $63 \%$ graduate from the program at the end in grade 12 . The rest either drop out or opt for other programs such as the gifted program. Of note, however, is that half of those who join universities manage to enroll in university courses that are taught exclusively in English, but only about $20 \%$ would make it to courses with strong bias in Mathematics.

\subsubsection{Written Test Results}

In the written tests, only about $36 \%$ of the students passed with a mean score of 50 and above when the test was done in English. This contrasts sharply with the results of the same test done in Thai language, 
where $63 \%$ of the students achieved a mean score of 50 and above. Out of 19 students, only 2 scored a clean A when the test was done in English, but 6 scored A when it was done in Thai language. The exact opposite holds true when it came to students who scored grade E, 6 for English and 2 for Thai language! Figure 3 below also depicts clearly that majority of the students' achievements in the test done in English fall in the average and below average categories. The positive skewness of the bell suggests a small number of students in the high and very high categories.

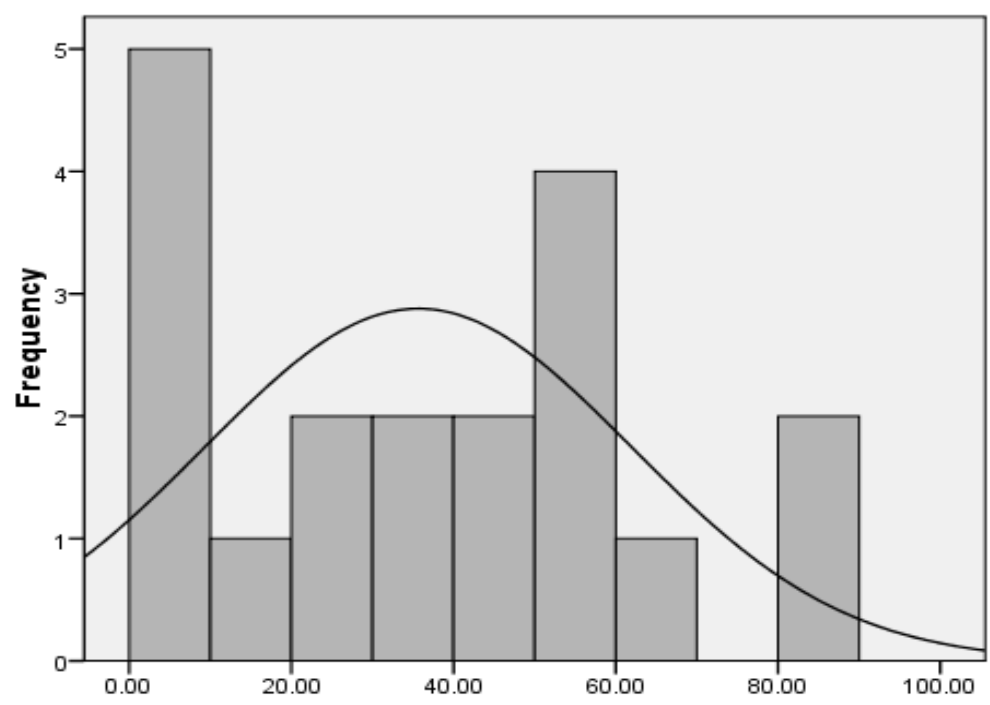

Figure 3 Distribution of the marks for the test done in English

Indeed it can be seen from the figure 4 that the shape of the bell is skewed in the opposite direction from that of figure 3 above. This suggests that majority of the students were within the 'high' and 'very high' categories.

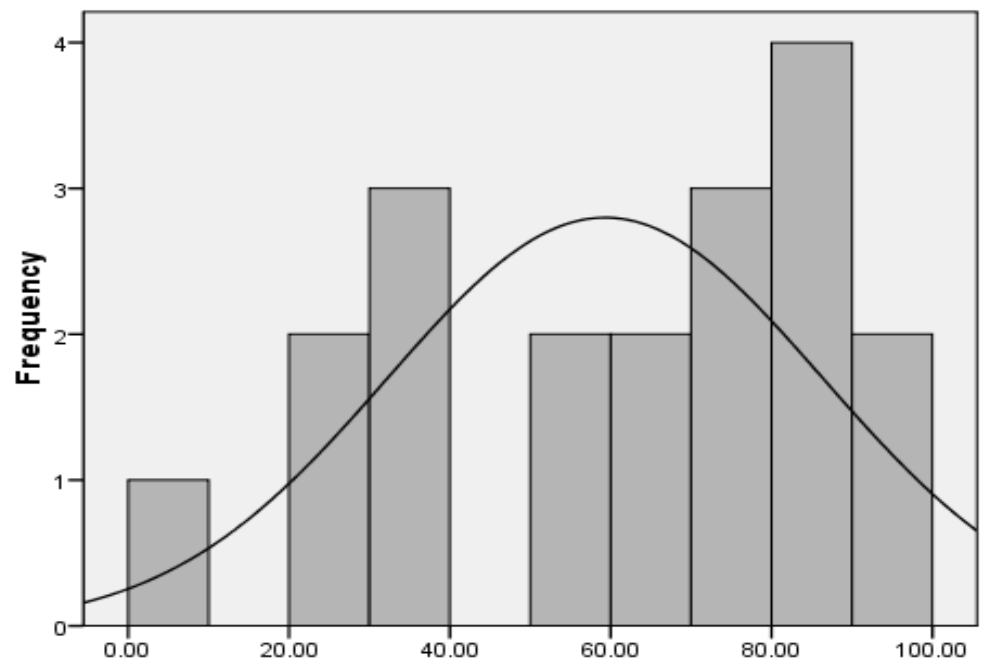


Figure 4: Distribution of the marks for the test done in Thai language

The results above are clearly summarized in the table below.

Table 4: Analysis of the Test Results

\begin{tabular}{|c|c|c|c|c|c|c|c|}
\hline Score & $\begin{array}{l}\text { Math in } \\
\text { English }\end{array}$ & Grade & $\begin{array}{c}\text { Math in } \\
\text { Thai }\end{array}$ & Grade & $\begin{array}{c}\text { Mean } \\
\text { Grade Eng. }\end{array}$ & $\begin{array}{c}\text { Mean Grade } \\
\text { Thai }\end{array}$ & Remark \\
\hline $75-100$ & 2 & $\mathrm{~A}$ & 6 & $\mathrm{~A}$ & 82 & 88.2 & Very High \\
\hline $70-74$ & 0 & $\mathrm{~B}+$ & 3 & $\mathrm{~B}+$ & & & \\
\hline $65-69$ & 0 & B & 0 & B & 64 & 68.4 & High \\
\hline $60-64$ & 1 & B- & 2 & B- & & & \\
\hline $55-59$ & 0 & $\mathrm{C}+$ & 0 & $\mathrm{C}+$ & & & \\
\hline $45-54$ & 6 & $\mathrm{C}$ & 2 & $\mathrm{C}$ & & & \\
\hline $40-44$ & 0 & $\mathrm{C}-$ & 0 & C- & 50.8 & 52 & Average \\
\hline $35-40$ & 0 & $\mathrm{D}+$ & 0 & $\mathrm{D}+$ & & & \\
\hline $30-34$ & 2 & $\mathrm{D}$ & 3 & $\mathrm{D}$ & & & \\
\hline $25-29$ & 1 & D- & 1 & D- & 144 & 25.3 & Below \\
\hline$\leq 24$ & 7 & $\mathrm{E}$ & 2 & $\mathrm{E}$ & 14.4 & & Average \\
\hline
\end{tabular}

Summary of the Research Findings

The research findings can be summed up as having looked at the Teachers' and Learners' Biodata in terms of gender, entry level grade or the grade level in which each individual learner joined the English program. The researcher also looked at effects of the use of English as a medium of instruction in the learning of Mathematics on the learners in terms of Communication, achievement, development in terms of Mathematics concepts acquisition and Opinions of the use of English as a Language of Instruction in Mathematics on Thai Learners. Finally, the chapter looked at the Implications of the use of English as a Medium of Instruction in the Learning of Mathematics on Thai learners.

\section{Discussions and Conclusions}

The teacher plays an important role in any classroom setting; this may be in form of helping students to grasp the concepts or simple things like helping learners understand the meaning of a given terminology. Whatever the role may be, it is always geared towards enabling students achieve their goal. Indeed the significant role of any classroom teacher in the process of learning is to facilitate learning. In order for teachers to facilitate learning, they must prepare lesson plans with simple language that learners can understand. This enables the teacher to transmit abstract concepts to the students only if they understand each other. Lack of proper communication in the classroom implies less meaningful learning in that classroom.

\subsection{Entry Grade Level}

The entry level grade was crucial to this study because if many students joined the program midway, it would compromise the results of the study because the English and Mathematics background of such students would have been factored in the study. But as it were, all the students sampled joined the program 
from lowest grade, which was grade 7 . This minimized the effect late entry would have on the results of the study.

\subsection{Effects of Using English to Instruct Students of Mathematics}

The study uncovered eight major effects that the use of English as a medium of instruction has on the learners of Mathematics.

\subsubsection{Wrong Perception}

Performance in mathematics by students in the English program is average at best, and in most cases below when compared to their counterparts in the Thai program. This has created a perception that either students are lazy or they naturally don't have what it takes to perform in Mathematics. But the study showed otherwise, that majority of the students in the English program are quite smart and are in fact able to achieve high grades in Mathematics under different circumstances. From figures 6 and 7 in chapter IV, we can clearly conclude that it is the language of instruction, in this case English language, which hinders students from achieving high grades in Mathematics. Therefore the thinking that students in the English Program are not Mathematics 'smart' is unfounded and nothing but a misperception. This problem would not have arisen if students were studying in their mother tongue or at least even through a second language because English is simply a foreign language to the students. Andoh-Kumi (2000) said that children learn better during the early years of their primary education when the medium of instruction is in the language they speak at home.

\subsubsection{Students' Motivation and Development}

Majority of students do not actually enjoy exercises in their text books, which leads us to conclude that many of them do not reach their full potential in Mathematics. These students have to deal with the Mathematics content, difficult as it may be, and at the same time deal with the difficulties inherent in the English language. They feel that it is problematic enough to study Mathematics and therefore should not enhance their problems by studying it using English. 'Mathematics content perceived difficulties' compounded with 'difficulties' of the English language weighs heavily on the students' motivation. Students should therefore be encouraged to go an extra mile in studying English language to counter this problem.

Group discussions are an integral part of the process of teaching and learning. Therefore in preparing for such an exercise requires that group dynamics are all carefully considered, and this includes the language they use in carrying out the activity. It is integral that the language used is clear and understandable by all the participants so as to attain maximum gains from the activity. But from the findings, majority of the learners do not understand or follow the proceedings when this is done through the English language, which means that majority do not contribute meaningfully to the discussions. Thai language being the learners' native language would be ideal for them in such circumstances, but this would present a challenge to the teachers who are foreign individuals.

\subsubsection{Time and Content Coverage}

For foreign language learners (FLL) or second language learners (SLL), language dictionaries are part and parcel of their everyday learning materials. Although Mathematics dictionaries are available, language 
dictionaries are still heavily used in the Mathematics classroom. In fact, it is a common practice for learners to ask permission to use dictionaries during continuous assessment tests and examinations. More often than not, their requests are granted, in the process, wasting a lot of time.

Although it is not recommended for teachers' rash through the syllabus with the aim of covering the content required by law, it is prudent that the pace be reasonable for both the students and the teacher. Majority of students do not understand English very well, so teachers are forced to speak slowly and repeatedly, hence covering very little. Students moving to higher grades without having properly covered the basics find it difficult to comprehend advanced topics for such levels. Learners then perceive mathematics as a difficult subject. Therefore, the learners should be well versed in the English language in order to study Mathematics through it. Even Anstrom, (1997) agreed that meeting curriculum standards will be disproportionately difficult for language-minority students since they will have to perform at much higher cognitive and linguistic levels than their native-speaking peers.

\subsubsection{Continuity}

Students join the English program for various reasons, but majority join because they wish to further their proficiency in English. This study shows that studying Mathematics in English helps students become better communicators in English. The consequences for this are that students are able to join international universities, some of which use English as the sole language of instruction. Although this is an excellent achievement on the part of the parties involved, the number of students who get to this level is significantly small. Therefore one wonders why students should spent six years studying through English and then end up in a Thai program in college or university. The effect of this is that students may pull out of the program or completely not join the program if they don't see how English will help them continue with their studies at an advanced level. Besides, students studying Mathematics in English sometimes encounter problems should they chose to leave the program and join other programs like the Thai normal program. This is because the students may not have covered required content for the level at which the student joins the other program due to the problems discussed above.

\subsubsection{Communication}

The study established that using English as a medium of instruction in Mathematics hampers communication. Many students who join the English program in grade 7 were not previously in English programs at their previous schools. The study also established that little communication takes place in Mathematics classrooms where English is used as a language of instruction. The large number of students who had difficulties in learning Mathematics through English proves that indeed communication is inhibited by the language. Many researchers including Frederick, (1991), McAndrews, (1991), and Taylor \& Tate, (1997) have shown that little or no significant learning takes place in a classroom where communication is one way business. One way communication is where a teacher talks at the learners without finding out whether learners are participating or not. Such students are not able to ask questions in class or even answer questions in class, therefore communicating to them is almost impossible. With a clear majority of students either unable or unwilling to ask or answer questions in class, the probability of any significant learning taking place in that classroom is very little. the method of communication

Indeed, Smith, (2017) concluded that for many students, what determines between success and failure in mathematics classrooms is the language used for instruction. However, the bright side to this is that 
teaching such students Mathematics using English eventually improves their communication competency, even though the pace of the Mathematics lessons would be very slow.

Reading

Reading is a very important part of speech that is essential in the teaching and learning process. Therefore, it is necessary that learners acquire sufficient reading skills in the language of instruction so that they can gain meaningful learning in a classroom. Cummins, (1979), postulate that if children are exposed to a home-school language switch, academic retardation is inevitable because children cannot learn through a language they do not understand. In Mathematics, reading is as important as it is in other subjects, with more emphasis placed on word problems. Data in this research reveals that almost half of the learners cannot read and understand their Mathematics text books. Textbooks and nowadays the internet provide supplementary information to the learners. In many cases, books and/or internet complement teachers and therefore it is paramount that learners utilize these resources maximally. In order to achieve this, learners must be able to not only read the books/internet but also critically analyze them, because not all the internet resources are authentic. Given the important role textbooks play, they should be structured in such a way that learners can easily read and understand the contents following it as it develops from one chapter to the next.

\subsubsection{General Performance}

In the education industry, some of the instruments used by teachers to gauge their students' level of understanding include continuous assessment tests (CAT) and main examinations. Students themselves also use such instruments to assess how much knowledge they may have gained prior to the evaluation time. These instruments may not be ideal but have been used from time immemorial and still are being used even now in many places around the world. Therefore, in designing them, care should be taken to ensure that the language used is easily understandable by the learners. In the same way, performance of the students was also affected negatively by the inability by the teachers to cover the required Mathematics content, and therefore students were not well equipped with the necessary and sufficient skills to handle Mathematics problems. This, to some extend is due to the poor communication in the Mathematics classroom that forces teachers to proceed slowly. Cooper \& McIntyre, (1996) puts it that a distinctive feature of successful students is their ability to understand and use the vocabulary of subjects they study.

\subsection{Opinions of Thai Learners on Using English in Mathematics}

The study established that learners had a number of opinions on using English as a language of instruction in Mathematics. It was also discovered that the learners have a strained but positive attitude towards the use of English as a medium of instruction.

\subsubsection{Opinions}

This research found out that learners prefer to have supplementary lessons taught in Thai language, some difficult concepts in the textbook to have some explanation in Thai language, and to be able to explain those concepts or advanced courses in Thai language. The learners' opinions would be summed up as a desire to have code-switching in their Mathematics classrooms. Codeswitching is not a new phenomenon as is considered to be a useful pedagogical tool in that it provides an additional resource for aiding 
understanding (Setati, 1998; Adler, 2001). MacGregor (1993) also found that international research strongly recommends systematic language support, code-switching, for the learning of Mathematics.

\subsubsection{Attitude}

As mentioned above, learners experience a strained but positive attitude towards the use of English as a medium of instruction. The intricate relationship between the love of mathematics and the difficulties experienced by using English is brought about by the fact that students do not hate English; rather they don't really appreciate it being used in other subjects. They believe this hinders them from achieving higher grades in those subjects, especially mathematics. These results are not isolated; Papanastasiou (2002) also found the existence of a positive relation between attitude and Mathematics achievement. But Ma \& Kishor (1997) concluded that although statistically significant, the mean effect size for the relationship between attitude towards Mathematics and achievement in Mathematics was not strong enough to have useful implications for educational practice.

\subsection{Implications Using English in Mathematics on Thai Learners}

The implications are evident and far reaching on the learners. The positive implications include admission in international universities, and enrolment in courses that are taught exclusively in English. All these lead to better and competitive job offers in the long run. Learners who graduate from grade 9 and are not willing to continue with the program find it easy to joint top ranking high schools that specializes in particular areas, for example a science only school or perhaps language schools. However, there are negative implications as well, for instance not all learners who are not able to continue with the program after grade 9 join good institutions. Some are not able to find better options and therefore end in any other available program, which is considered a waste of 3 years in the English program. Still even those who graduate from grade 12 and are not able to join university courses that have a direct bearing on Mathematics or English would find it difficult to see or experience benefits that justify their six years spent in the English program. Schwartz, (1991) concurs with these findings when he says that 'understanding and using mathematics are increasingly crucial to an individual's ability to function in society and succeed in the job market'.

\section{Conclusions}

From the findings of this study, it is concluded that the use of English as a medium of instruction has significant effects on the learning of Mathematics. It makes it more difficult for learners to achieve high grades as compared to learning Mathematics in the native Thai language. The research hypothesis, as shown by the two tailed t-test in the appendix, is therefore not rejected at 0.000 level of significance.

\section{Recommendations}

Based on the findings, the researcher recommends that both students and parents be made aware of the importance of students' competency in English if they are to achieve high grades in Mathematics. Also, school administrators should organize voluntary supplementary classes for students who are most affected by the English language. Lastly, students should be made aware of the implications or be aware of the advantages and disadvantages of studying Mathematics in English before they make their choices. 


\section{References}

Adler, J. (2001). Teaching mathematics in multilingual classrooms. Dortrecht: Kluwer Academic Publisher.

Ames, C. (1984). Competitive, cooperative, and individualistic goal structures: A cognitive-motivation analysis. In R. Ames \& C. Ames (Eds.). Research in motivation in education: Student motivation_(pp. 177-207). New York: Academic Press.

Andoh-Kumi. (2000). "One Policy, Many Needs." Unpublished paper presented at the Comparative and International Education Society (CIES) Conference in San Antonio, USA, March 2000.

Anstrom, K. (1997). Academic achievement for secondary language minority students: Standards, measures and promising practices. Retrieved on April 14 at http://www.ncela.gwu.edu/pubs/reports/acadach.htm

Cooper, P., \& McIntyre, D. (1996). Effective teaching and learning: Teachers' and students' perspectives. McGraw-Hill Education (UK).Crandall, J. (Ed.). (1987). ESL through content-area instruction: Mathematics, science, social Studies. Englewood Cliffs, NJ: Prentice Hall Regents Center for Applied Linguistics.

Cummins, J. (1979). Cognitive/academic language proficiency, linguistic interdependence, the Optimum age question and some other matters. Working Papers on Bilingualism, 19, 121-129.

Danielson, C. (2007). Enhancing professional practice: A framework for teaching (2nd ed.). Alexandria, VA: Association for Supervision and Curriculum Development.

Darling, F., \& Darling, A. (1971). Thailand: The modern kingdom. Singapore: Asia Pacific Press.

Francis, D.J., Riviera, M., Lesaux, N., Kieffer, M., \& Riviera, H. (2006) Researched-based recommendations for instruction and academic interventions. Portsmouth, $\mathrm{NH}$ : Center on Instruction. Retrieved 16/06/09.

Frederick, P.J. (1991). Active learning in history classes. Teaching History, 16(2), 67-83.

Freeman, B. (2012). Using digital technologies to redress inequities for English language learners in the English speaking mathematics classroom. Computers \& Education, 59(1), 50-62.

Gagné, R.M. (1985). The conditions of learning and theory of instruction (4th Ed.). New York: Holt, Rinehart and Winston.

Hornby, S. A. (2005). Advanced learners' dictionary. Oxford.

Taylor, A. \& Tate, D. (1997). Flip it! And you be the judge: Two cooperative-learning activities to teach foreign languages. Cooperative Learning and College Teaching, 7(2), 5-7.

Ma, X., \& Kishor, N. (1997). Assessing the relationship between attitude toward mathematics and achievement in mathematics: A meta-analysis. Journal for Research in Mathematics Education, 26-47.

MacGregor, M. (1993). Teaching Mathematics in English to Students of Non-English-Speaking Background. Multicultural Teaching, 11(3), pp.31-34.

McAndrews, L.J. (1991). Tearing down the wall: Adventures in active learning. The History Teacher, 25(1), 35-43.

Papanastasiou, C. (2002). Effects of background and school factors on the mathematics achievement. Educational Research and Evaluation, 8(1), 55-70.

Post, R. (2009). Teaching mathematics in grades $K$-: Research-based methods. Minesota: Allyn and Bacon, 1992.

Ryan, M. (2003). Ask the teacher: A practitioner's guide to teaching and learning in the diverse classroom. Boston: Chestnut Hill Enterprises.

Rovinelli, R. J., \& Hambleton, R. K. (1977). The use of content specialists in the assessment of criterionreferenced test item validity: 1977. Dutch J Edu Res.

Sangnapabowon, W. (2003). Higher education reform in Thailand towards quality improvement and university autonomy. Approaches to higher education, intellectual creativity, cultivation of human resources seen in Asian countries. Tokyo, Shizuoka Research Institute. 
Schwartz, W. (1991). Teaching limited English proficient students to understand and use mathematics. ERIC/CUE Digest No. 70.

Setati, M. (1998). Code-Switching in a senior primary class of second-language learners. For the Learning of Mathematics, 18(1), pp.34-40.

Smith, O. S. O. (2017). The Influence of language on the teaching and learning of mathematics.

Steele, C. F. (2009). Inspired teacher: How to know one, grow one, or be one. Alexandria, VA: Association for Supervision and Curriculum Development. Retrieved from http://www.ascd.org/publications/books/108051.aspx

Stigler, J. W., \& Hiebert, J. (2004, Feb). Improving Mathematics instruction. Educational Leadership, 61(5), 12-17.

Tripasai, P. (2005). Debating Anna: The textual politics of English literature teaching in Thailand. In Doing the Public Good: Positioning Education Research. Australian Association for Educational Research 2004 Conference Papers (pp. 1 - 18). Australian Association for Research in Education.

Troutman, A, P. \& Lichtenberg B, K. (2003). Mathematics: A good beginning. $6^{\text {th }}$ edn. Belmont: Thomson Wadsworth.

Van, H. (1984). A child's thought in geometry. In: D Fuys, D Geddes \& R Tischle r (eds). English translation of selected writings of Dina van Hile-Geldof and PM van Hieles (243-252). Columbus, OH: ERIC. 
International Journal of Social Sciences \& Educational Studies ISSN 2520-0968 (Online), ISSN 2409-1294 (Print), June 2020, Vol.7, No.2

\section{APPENDIX}

Table 5: The t-Statistic Test Results

Paired Samples Test

\begin{tabular}{|c|c|c|c|c|c|c|c|c|}
\hline & \multicolumn{5}{|c|}{ Paired Differences } & $\mathrm{t}$ & df & $\begin{array}{l}\text { Sig. }(2- \\
\text { tailed) }\end{array}$ \\
\hline & \multirow[b]{2}{*}{ Mean } & \multirow{2}{*}{$\begin{array}{c}\text { Std. } \\
\text { Deviation }\end{array}$} & \multirow{2}{*}{$\begin{array}{l}\text { Std. Error } \\
\text { Mean }\end{array}$} & \multicolumn{2}{|c|}{$\begin{array}{l}95 \% \text { Confidence Interval } \\
\text { of the Difference }\end{array}$} & & & \\
\hline & & & & Lower & Upper & & & \\
\hline $\begin{array}{ll}\text { Pair } 1 \text { MathEng - } \\
\\
\text { MathThai }\end{array}$ & $-2.36789 \mathrm{E} 1$ & 19.07391 & 4.37585 & -32.87228 & -14.48562 & -5.411 & 18 & .000 \\
\hline
\end{tabular}

